\title{
Hilar lymphadenopathy, a novel finding in the setting of coronavirus disease (COVID-19): a case report
}

\author{
Mohsin Sheraz Mughal ${ }^{1 *}$ (D, Rameez Rehman ${ }^{1}$, Ramy Osman ${ }^{1}$, Nathan Kan ${ }^{1}$, Hasan Mirza ${ }^{2}$ and Margaret H. Eng ${ }^{1}$
}

\begin{abstract}
Background: As the outbreak of coronavirus disease 2019 (COVID-19) has progressed, computed tomography has emerged as an integral part of the diagnosis alongside reverse transcriptase-polymerase chain reaction assays. Frequently encountered imaging findings include peripheral airspace consolidations; bilateral ground-glass opacities; and, less commonly, cavitation. Hilar lymphadenopathy is a rarely reported finding in the setting of COVID-19.

Case presentation: A 73-year-old Caucasian woman presented to our hospital with fever and fatigue. She had a maximum body temperature of $102.3^{\circ} \mathrm{F}$ with lymphopenia and thrombocytopenia. She was diagnosed with severe acute respiratory syndrome coronavirus 2 infection on the basis of a positive result from a reverse transcriptasepolymerase chain reaction of a nasopharyngeal swab sample. Contrast-enhanced chest computed tomography revealed multifocal, subpleural ground-glass opacities with nodular consolidations bilaterally. Computed tomography also demonstrated atypical bilateral hilar lymphadenopathy, a rarely reported imaging feature of COVID-19. Chest computed tomography 1 month before the presentation did not show focal consolidations or lymphadenopathy. This indicated that the findings were due to the patient's severe acute respiratory syndrome coronavirus 2 infection. She received 5 days of oral hydroxychloroquine and experienced resolution of her symptoms.

Conclusion: Chest computed tomography has been used extensively to diagnose and characterize the distinguishing radiological findings associated with viral pneumonia. It has emerged as an integral part of the diagnosis of COVID-19 alongside reverse transcriptase-polymerase chain reaction assays. Clinicians must be aware of uncommon clinical and radiological findings in order to diagnose this entity. Hilar lymphadenopathy is commonly seen with fungal infections, mycobacterial infections, and sarcoidosis. An extensive literature review found that bilateral hilar lymphadenopathy has not been reported in the setting of COVID-19. More data are needed to establish the clinical impact of this novel finding.
\end{abstract}

Keywords: Coronavirus, Lymphadenopathy, Viral pneumonia, COVID-19

\section{Introduction}

The World Health Organization declared coronavirus disease 2019 (COVID-19) a pandemic in March 2020.

\footnotetext{
* Correspondence: mohsinsherazmd@gmail.com

${ }^{1}$ Monmouth Medical Center, An Affiliate of RWJ/Barnabas Health System, 300 2nd Avenue, Long Branch, NJ 07740, USA

Full list of author information is available at the end of the article
}

Though the incidence of the disease has drastically dropped in China, it is rising worldwide [1]. Coronavirus is an encapsulated ribonucleic acid (RNA) virus, a novel coronavirus named severe acute respiratory syndrome coronavirus 2 (SARS-CoV-2), which was identified as the culprit of a cluster of lower respiratory tract illnesses in Wuhan, China. A study suggested that it has two

(c) The Author(s). 2020 Open Access This article is licensed under a Creative Commons Attribution 4.0 International License, which permits use, sharing, adaptation, distribution and reproduction in any medium or format, as long as you give appropriate credit to the original author(s) and the source, provide a link to the Creative Commons licence, and indicate if changes were made. The images or other third party material in this article are included in the article's Creative Commons licence, unless indicated otherwise in a credit line to the material. If material is not included in the article's Creative Commons licence and your intended use is not permitted by statutory regulation or exceeds the permitted use, you will need to obtain permission directly from the copyright holder. To view a copy of this licence, visit http://creativecommons.org/licenses/by/4.0/ The Creative Commons Public Domain Dedication waiver (http://creativecommons.org/publicdomain/zero/1.0/) applies to the data made available in this article, unless otherwise stated in a credit line to the data. 
strains: type $\mathrm{S}$ and type $\mathrm{L}$ [2]. The understanding of the disease, its transmission, and its treatment are still evolving. COVID-19 can range from being asymptomatic to a wide variety of severe symptoms [3]. Several observational studies suggested that fever, malaise, dry cough, and dyspnea are the most common presenting symptoms [4]. As the outbreak of COVID-19 has progressed, so have the methodologies used in its diagnostic workup. A chest computed tomographic (CT) scan has quickly emerged as an integral part of the diagnosis alongside reverse transcriptase-polymerase chain reaction (RTPCR) assays [5]. The most commonly reported CT findings in patients with COVID-19 are bilateral groundglass opacities [6]. In another study, CT manifestations were peripheral airspace consolidations in one-third of the cases. Less common findings include pleural effusion, pericardial effusion, cavitation, air bronchograms, and pneumothorax [7]. These data are helpful for clinicians to gain an understanding of a wide spectrum of imaging findings in patients with COVID-19. Hilar lymphadenopathy is a common radiological finding associated with fungal infections, mycobacterial infections, and sarcoidosis. However, it is rarely seen in viral pneumonia. Because the COVID-19 pandemic is affecting healthcare and economic systems worldwide, it is imperative to detect the disease earlier in the course before complications involving acute hypoxic respiratory failure warranting invasive mechanical ventilation arise. Characteristic CT scan findings, alongside RT-PCR and antibody testing, help clinicians diagnose COVID-19. None of these modalities can be used as a single tool to diagnose SARS-CoV-2 infection. An extensive literature review found that acute bilateral hilar lymphadenopathy has not been reported in the setting of COVID-19 [6, 8]. It is important to report atypical imaging findings to establish their frequency and association with disease severity and outcomes.

\section{Case presentation}

A 73-year-old Caucasian woman with a past medical history of hypertension, hyperlipidemia, pulmonary embolism, and rheumatoid arthritis came to our emergency department with complaints of fever, chills, generalized weakness, and decreased appetite of 1 day's duration. Her home medication list included amlodipine $10 \mathrm{mg}$, pantoprazole $40 \mathrm{mg}$, rivaroxaban $20 \mathrm{mg}$, and omega- 3 polyunsaturated fatty acid $1000 \mathrm{mg}$. The patient had a remote history of rheumatoid arthritis, for which she was not taking any medication. She had quit smoking almost 30 years ago and admitted to one or two glasses of alcohol consumption occasionally. In the emergency department, she was febrile with a maximum body temperature of $102.3^{\circ} \mathrm{F}$. Her blood pressure was $157 / 73$ $\mathrm{mmHg}$, heart rate was 81 beats/minute, respiratory rate was 16 breaths/minute, and pulse oxygen saturation was $96 \%$ on room air. At admission, she was alert and oriented and did not seem to be in any distress. Her pulse was regular; her heart sounds (S1, S2) were audible without any murmur or additional heart sounds; and no lower extremity edema was observed during her physical examination. Her lungs were grossly clear with equal air entry without any wheeze or rhonchi. Her abdomen was soft, and bowel sounds were present. Her hematological workup showed leukopenia (white blood cell count, $3400 / \mathrm{mm}^{3}$ ), anemia (hemoglobin, $10.5 \mathrm{~g} / \mathrm{dl}$ ), thrombocytopenia (platelets, $163,000 / \mathrm{mm}^{3}$ ), and elevated inflammatory markers including $\mathrm{C}$-reactive protein $(66.8 \mathrm{mg} / \mathrm{L})$ and erythrocyte sedimentation rate $(74 \mathrm{~mm} /$ hour). The result of multiplex respiratory viral polymerase chain reaction (PCR) was negative for respiratory tract viral infections. Liver function tests, including aspartate aminotransferase $(26 \mathrm{U} / \mathrm{L})$ and alanine aminotransferase (ALT $8 \mathrm{U} / \mathrm{L}$ ), and a basic metabolic panel, including blood urea nitrogen $(16 \mathrm{mg} / \mathrm{dl})$ and creatinine $(1.03 \mathrm{mg} / \mathrm{dl})$, were within the normal ranges. The result of a nasopharyngeal (NP) swab sample for SARS-CoV-2 was positive by RT-PCR, and a diagnosis of COVID-19 was established. Blood cultures and sputum culture did not show any bacterial or fungal growth. The patient started developing a dry cough and respiratory distress requiring supplemental oxygen via a nasal cannula (up to $6 \mathrm{~L} /$ minute) on the second day of admission with sporadic rhonchi detected by physical examination. Contrast-enhanced chest CT revealed multifocal, subpleural ground-glass opacities with nodular consolidations bilaterally (Fig. 1a, b). A CT scan also demonstrated atypical bilateral hilar lymphadenopathy, a rarely reported CT finding in COVID-19 (Fig. 2a). Chest CT one month before the current presentation demonstrated no focal consolidations or lymphadenopathy (Fig. 2b). The patient received hydroxychloroquine (HCQ) $200 \mathrm{mg}$ and azithromycin $500 \mathrm{mg}$ orally for 5 days alongside supportive treatment with acetaminophen and supplemental oxygenation via nasal cannula. Her fever resolved, and her respiratory status improved. At discharge, she was breathing without any distress on room air.

\section{Discussion}

Chest CT has been used extensively not only to diagnose but also to characterize the distinguishing radiological findings associated with viral pneumonia. SARS-CoV-2 is diagnosed by COVID-19 symptomatology and RTPCR with NP swabs. As the outbreak of COVID-19 has progressed, CT alongside RT-PCR has been used broadly to diagnose COVID-19 [9]. There is convincing evidence that viral load is high in NP samples, and RT-PCR can have false-positive and false-negative results. If there is a high clinical suspicion, then repeat RT-PCR with 


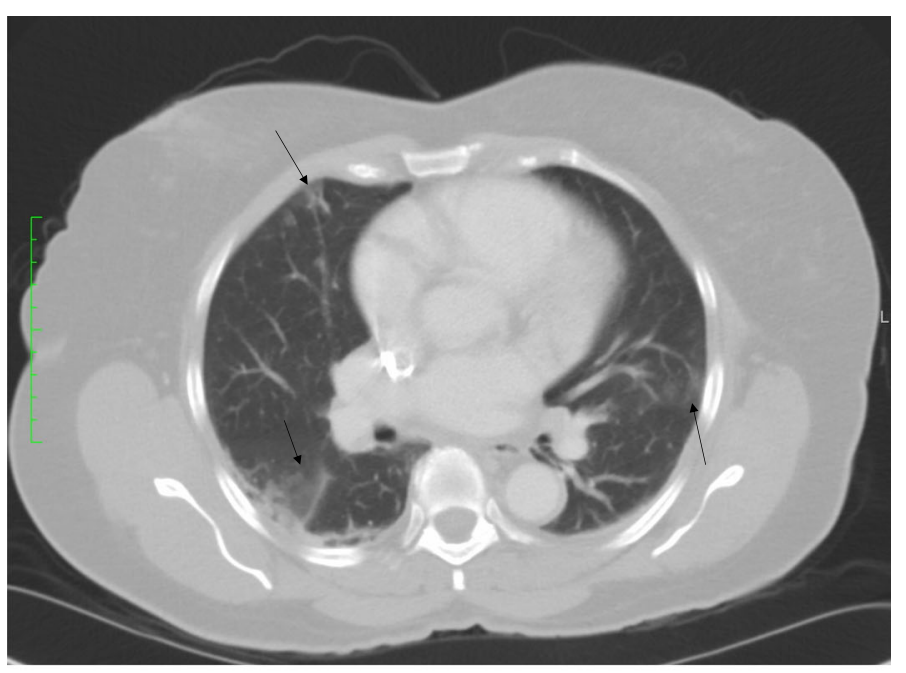

A - multifocal, ill defined subpleural ground glass attenuation opacities are seen bilaterally

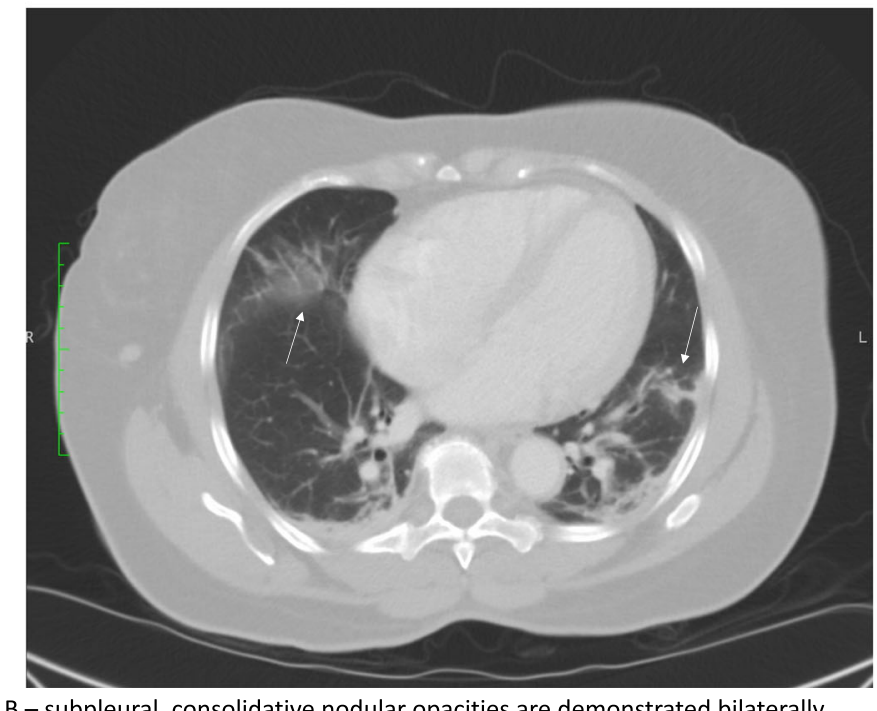

B - subpleural, consolidative nodular opacities are demonstrated bilaterally

Fig. 1 Contrast-enhanced chest computed tomography reveals multifocal, subpleural ground-glass attenuation opacities (arrow) (a) with nodular consolidations bilaterally (arrow) (b)

resampling from another site is recommended [10]. There have been patients with a negative result of RTPCR but whose CT scan was suggestive of viral pneumonia. Later, those patients had positive test results for SARS-CoV-2 $[11,12]$. Yan Li and Liming Xia suggested that $\mathrm{CT}$ scans can be used as a rapid diagnostic tool to diagnose COVID-19 on the basis of a low rate of missed diagnoses [13]. This argues in favor of chest imaging earlier in the course with clinical suspicion of viral pneumonia. Frequently encountered imaging findings include peripheral airspace consolidations and bilateral groundglass opacities; less common associations include cavitation and air bronchograms. To our knowledge, hilar lymphadenopathy has not been reported in the setting of COVID-19. RT-PCR of the NP swab sample is the preferred and recommended screening test worldwide. However, false-negative results may occur because of inadequate viral load or impaired sampling techniques. In these circumstances, chest CT scans and SARS-CoV-2 immunoglobulin $\mathrm{M}$ antibody testing can significantly aid in the diagnostic workup. CT scan findings can vary on the day of imaging, and some studies even suggested obtaining a repeat CT scan to rule out worsening of the disease [14]. Clinicians must be aware of rare clinical and radiological findings in order to diagnose this entity. In the absence of effective antiviral therapy and persistent evidence-based guidelines, HCQ and zinc were initially used for COVID-19. Interleukin-6 inhibitors are used against the hyperinflammatory state because of the proposed cytokine storm syndrome. Immunoglobulin G 


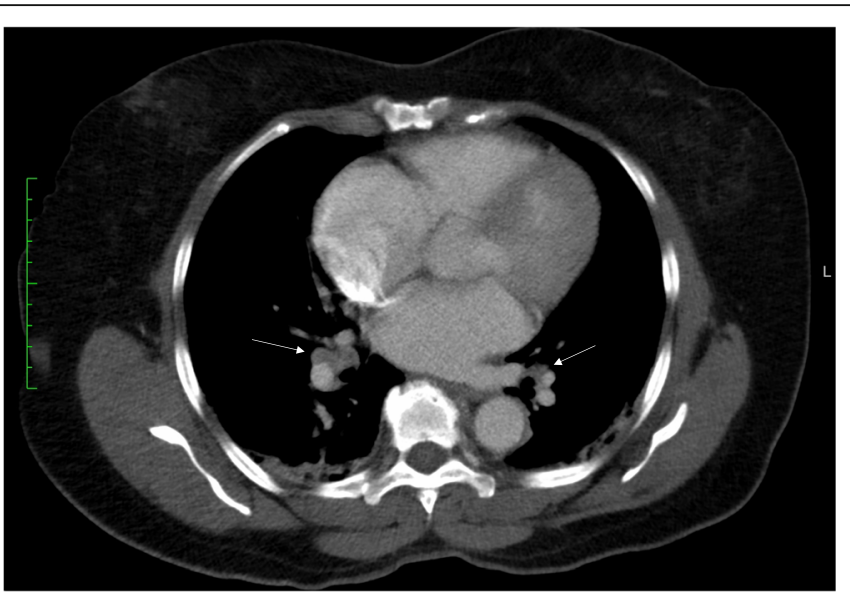

A - bilateral hilar adenopathy, right sided greater than left
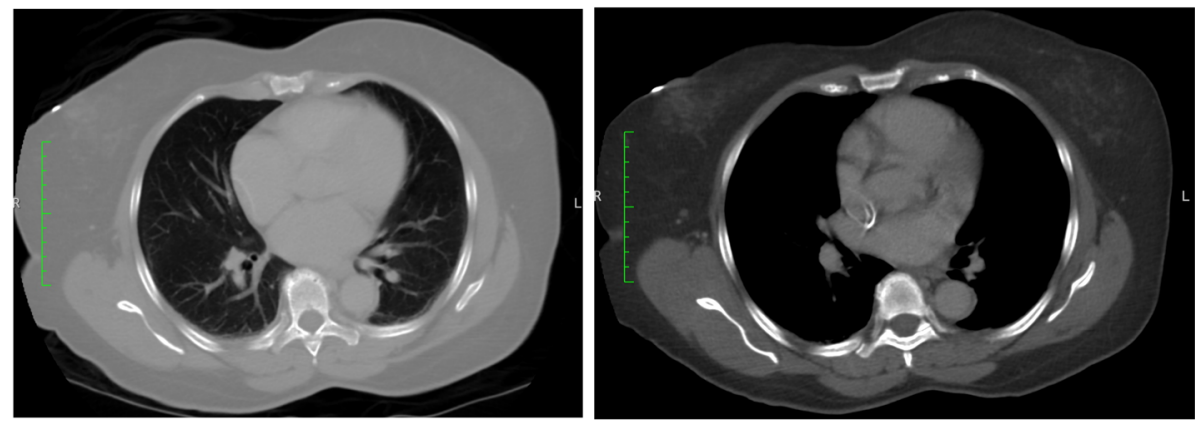

B - chest CT findings one month prior to presentation demonstrate no focal consolidations and no evidence of hilar lymphadenopathy

Fig. 2 a Atypical bilateral hilar lymphadenopathy (arrow), a novel finding of coronavirus disease 2019. b Chest computed tomography 1 month before presentation demonstrates no focal consolidations and no lymphadenopathy

antibodies against SARS-CoV-2 start developing after 2 weeks of disease onset, and convalescent plasma from the recovered patient population is being studied in compassionate trials at different centers. The efficacy of these medications and therapeutic interventions is yet to be established. Calcified lymph nodes have been reported in the late stages of alphaherpesvirus pneumonia [15]. However, bilateral hilar lymphadenopathy has not been reported in the setting of COVID-19. Reporting and recognizing the rare imaging findings will help clinicians to understand their frequency and association with the disease. Follow-up imaging should be pursued to evaluate the persistence or resolution of hilar lymphadenopathy. More information with long-term follow-up is required to establish the importance and clinical implications of our findings.

\section{Conclusion}

Chest CT has been used extensively to diagnose and characterize the distinguishing radiological findings associated with viral pneumonia. It has emerged as an integral part of the diagnosis of COVID-19 alongside RTPCR. Clinicians must be aware of uncommon clinical and radiological findings in order to diagnose this entity. Hilar lymphadenopathy is commonly seen with fungal infections, mycobacterial infections, and sarcoidosis. In an extensive literature review, bilateral hilar lymphadenopathy was not reported in the setting of COVID-19. Recognizing rare imaging findings will help clinicians understand their frequency and association with disease severity. Follow-up imaging should be pursued to evaluate the persistence or resolution of hilar lymphadenopathy in patients with COVID-19.

\section{Acknowledgements}

The authors thank Ikwinder Preet Kaur, MD, and Wael Ghali, MD, for their assistance.

\section{Authors' contributions}

MSM wrote the primary manuscript. RR and NK helped with the radiological data. HM and RO helped with the literature review. MHE revised and critically reviewed the final manuscript. All authors read and approved the final manuscript.

\section{Funding}

Not applicable.

Availability of data and materials Not applicable. 
Ethics approval and consent to participate

Not applicable.

\section{Consent for publication}

Written informed consent was obtained from the patient for publication of this case report and any accompanying images. A copy of the written consent is available for review by the Editor-in-Chief of this journal.

\section{Competing interests}

The authors declare that they have no competing interests.

\section{Author details}

'Monmouth Medical Center, An Affiliate of RWJ/Barnabas Health System, 300 2nd Avenue, Long Branch, NJ 07740, USA. ${ }^{2}$ Beth Israel Deaconess Medical Center/Harvard Medical School, Boston, MA, USA.

Received: 9 April 2020 Accepted: 8 July 2020

Published online: 09 August 2020

\section{References}

1. Johns Hopkins Coronavirus Resource Center. COVID-19 dashboard. https://coronavirus.jhu.edu/map.html. Accessed 25 March 2020

2. Tang X, Wu C, Li X, Song Y, Yao X, Wu X, Duan Y, Zhang H, Wang Y, Qian Z, Cui J, Lu J. On the origin and continuing evolution of SARS-CoV-2. Natl Sci Rev. 2020;7:1012-23. https://doi.org/10.1093/nsr/nwaa036.

3. Wang Y, Liu Y, Liu L, Wang X, Luo N, Li L. Clinical outcomes in 55 patients with severe acute respiratory syndrome coronavirus 2 who were asymptomatic at hospital admission in Shenzhen, China. J Infect Dis. 2020; 221:1770-4. https://doi.org/10.1093/infdis/jiaa119.

4. Wang D, Hu B, Hu C, Zhu F, Liu X, Zhang J, Wang B, Xiang H, Cheng Z, Xiong Y, Zhao Y, Li Y, Wang X, Peng Z. Clinical characteristics of 138 hospitalized patients with 2019 novel coronavirus-infected pneumonia in Wuhan, China. JAMA. 2020;323(11):1061-9. https://doi.org/10.1001/jama. 2020.1585 .

5. Ai T, Yang Z, Hou H, Zhan C, Chen C, Lv W, Tao Q, Sun Z, Xia L. Correlation of chest CT and RT-PCR testing for coronavirus disease 2019 (COVID-19) in China: A report of 1014 cases. Radiology. 2020;296(2):E32-E40. https://doi.org/10.1148/radiol.2020200642.

6. Chung M, Bernheim A, Mei X, Zhang N, Huang M, Zeng X, Cui J, Xu W, Yang Y, Fayad ZA, Jacobi A, Li K, Li S, Shan H. CT imaging features of 2019 novel coronavirus (2019-nCoV). Radiology. 2020;295(1):202-7. https://doi.org/10.1148/radiol.2020200230.

7. Salehi S, Abedi A, Balakrishnan S, Gholamrezanezhad A. Coronavirus disease 2019 (COVID-19): a systematic review of imaging findings in 919 patients. AJR Am J Roentgenol. 2020;215(1):87-93. https://doi.org/10.2214/ajr.20. 23034.

8. Ng M, Lee EY, Yang J, Yang F, Li X, Wang H, Lui MM, Lo CS, Leung B, Khong $P$, Hui CK, Yuen $K$, Kuo MD. Imaging profile of the COVID-19 infection: radiologic findings and literature review. Radiol Cardiothorac Imaging. 2020; 2(1):e200034. https://doi.org/10.1148/ryct.2020200034.

9. Patel A, Jernigan DB. 2019-nCoV CDC Response Team. Initial public health response and interim clinical guidance for the 2019 novel coronavirus outbreak — United States, December 31, 2019-February 4, 2020. MMWR Morb Mortal Wkly Rep. 2020;69:140-6. A published erratum appears in MMWR Morb Mortal Wkly Rep. 2020;69(6):173.

10. World Health Organization (WHO). Technical guidance on COVID-19: surveillance and case definitions. Geneva: WHO. https://www.who.int/ emergencies/diseases/novel-coronavirus-2019/technical-guidance/ surveillance-and-case-definitions. Accessed 28 Feb 2020.

11. Xie X, Zhong Z, Zhao W, Zheng C, Wang F, Liu J. Chest CT for typical 2019nCoV pneumonia: relationship to negative RT-PCR testing. Radiology. In press; https://doi.org/10.1148/radiol.2020200343.

12. Shi H, Han X, Jiang N, Cao Y, Alwalid O, Gu J, Fan Y, Zheng C. Radiological findings from 81 patients with COVID-19 pneumonia in Wuhan, China: a descriptive study. Lancet Infect Dis. 2020;20:425-34. https://doi.org/10.1016/ s1473-3099(20)30086-4

13. Li Y, Xia L. Coronavirus disease 2019 (COVID-19): Role of chest CT in diagnosis and management. Am J Roentgenol. 2020;214(6):1280-6. https://doi.org/10.2214/ajr.20.22954.
14. Pan $F, Y e T$, Sun $P$, et al. Time course of lung changes at chest $C T$ during recovery from coronavirus disease 2019 (COVID-19). Radiology. 2020;295(3): 715-21. https://doi.org/10.1148/radiol.2020200370.

15. Koo HJ, Lim S, Choe J, Choi S, Sung H, Do K. Radiographic and CT features of viral pneumonia. Radiographics. 2018;38(3):719-39. https://doi.org/10. 1148/rg.2018170048

\section{Publisher's Note}

Springer Nature remains neutral with regard to jurisdictional claims in published maps and institutional affiliations.

\section{Ready to submit your research? Choose BMC and benefit from:}

- fast, convenient online submission

- thorough peer review by experienced researchers in your field

- rapid publication on acceptance

- support for research data, including large and complex data types

- gold Open Access which fosters wider collaboration and increased citations

- maximum visibility for your research: over $100 \mathrm{M}$ website views per year

At BMC, research is always in progress.

Learn more biomedcentral.com/submissions 